\title{
A Preliminary Study on Social Cues Design in Mobile Check-in Based Advertisement
}

\author{
Chi-Lun Liu ${ }^{1, *}$ and Hsieh-Hong Huang ${ }^{2}$ \\ ${ }^{1}$ Department of Multimedia and Mobile Commerce, Kainan University, 1, \\ Kainan Road, Luzhu, Taoyuan 33857, Taiwan \\ tonyliu@mail.knu.edu.tw \\ ${ }^{2}$ Dept. of Information Science and Management Systems, \\ National Taitung University, 684, Sec. 1, Chunghua Road, Taitung 95002, Taiwan \\ kory@nttu.edu.tw
}

\begin{abstract}
Companies consider the check-in service as an new advertising channel to promote the companies and products. The check-in based advertisement always has different level of social cues richness. Determining an effective social cues design in check-in based advertisement is a critical question. This research explores which social cues design will be appropriate in check-in based advertisement. The results of a laboratory experiment supported that the design of higher social cues richness increases higher advertising effectiveness measured by attitude toward the ad in general. Social media users would intend to use the appropriate design if the design is effective and easy-to-be-memorized.
\end{abstract}

Keywords: Social cues, attitude toward the ad, mobile check-in apps, social media, mobile marketing.

\section{Introduction}

Social media, such as Facebook, is one of the most popular website in many people's personal life. For the marketing purpose, social media is emergent as a powerful communication tool has made it possible for a person to communicate hundreds or thousands of other people about products and companies informally (Mangold and Faulds, 2009). Many people like to use check-in services in social media to post messages and photos about their lives in particular locations. Check-in service is a one-tomany model that allows users to semantically create and name venues to manually broadcast their locations to their friends in social media (Cramer et al., 2011). Posted content included messages and photos usually involve companies and products, such as meals in a restaurant and facilities in an amusement park. Therefore the content posted by consumers in a check-in service can be considered as a new informal form of advertisement for companies' marketing and promotion.

Social cues refer to a medium presents other persons' social interactions directly or indirectly (Kamins, 2011; Horvath and Lombard, 2010). The content posted by check-in

\footnotetext{
* Corresponding author.
} 
service users always have different levels of social cues richness. For example, the content including no photo has fewer social cues than the content including photo. Users' attitude toward the content which have different social cues in check-in services is an interesting issue for internet marketing. In the other hand, check-in service users preferring to post which level of social cues richness is another interesting research issue. Companies like positive and good messages about their companies and products.

The prior Human Computer Interaction (HCI) studies investigate on social cues presentation. For example, Horvath and Lombard (2010) use pleasantries in text and cartoon owl as high social cue conditions in information system interface. Wang et al. (2007) use animated character and real-person character as social cues on retail web sites. Kamins et al. (2011) focus on internet auctions and use the following information as social cues: the number of bids submitted, a counter which presents the number of viewers who watched the item on sale, and bidder's personal information. In the Hu and Jasper's study (2006), the store decorated with posters which showed a man, mother, and baby in high sociallyoriented display condition. The above prior studies investigate the effects of social cues outside the social app context because the social app context is a new phenomenon. Check-in Content in a social app is different from other apps because the content is often generated by a friend and includes location-based information.

The first research objective of this study aims to manipulate different levels of social cues richness in the check-in based advertisement and to explore how social cues designs influence audiences' attitude toward the ad. The second research objective of this study aims to explore the relationship between attitude toward the ad, self efficacy on recall, and usage intention for each social cues design when users post articles in a check-in service.

\section{Social Cues Design in Mobile Check-in Based Advertisement}

The Facebook app, which is a popular mobile check-in app on android platform, is chosen in the experiment. The Facebook app provides a location-based service and shows the check-in location in the map in the user-generated check-in content. The Facebook app users can alternatively post texts and photos when they check in. Three social cues designs are usually appears on user-generated check-in content in the real world: text, text and product photo, and text and product+person photo.

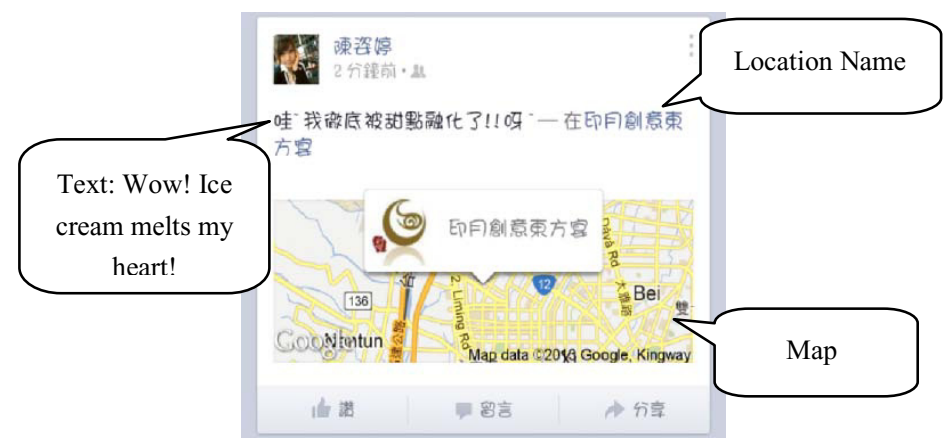

Fig. 1. Screenshot of social cues design C-1: Text 


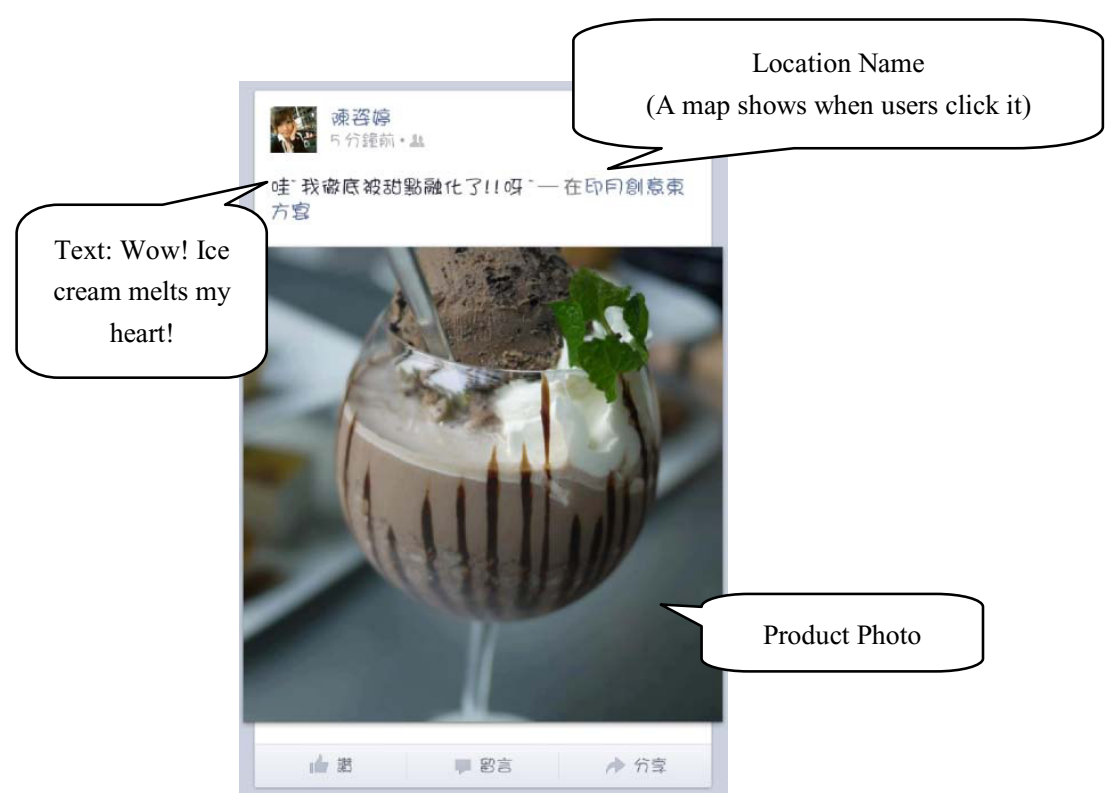

Fig. 2. Screenshot of social cues design C-2: Text and product photo

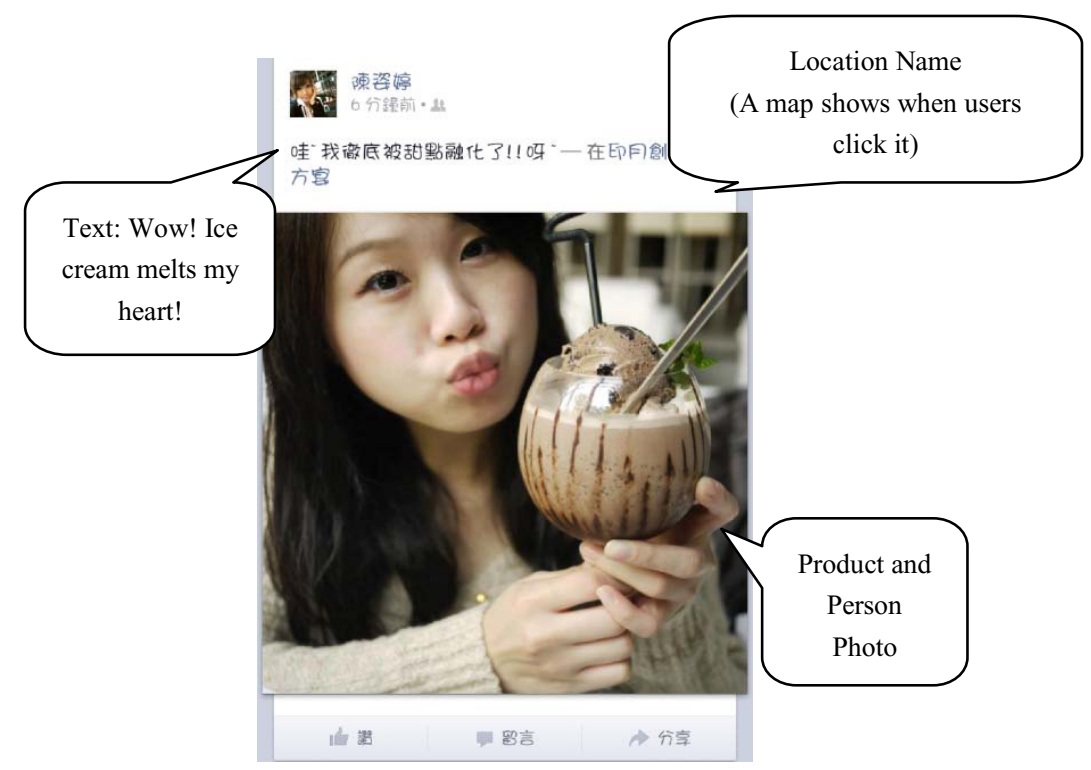

Fig. 3. Screenshot of social cues design C-3: Text and product+person photo 
This study uses the Facebook app and the mobile device, which is Samsung Galaxy S3, to manipulate three social cues design advertisement: C-1, C-2, and C-3. A user only input text data in social cues design C-1 (Fig. 1). A user input text data and a photo including ice cream product in social cues design C-2 (Fig. 2). And a user input text data and a photo including ice cream product and a person in social cues design C-3 (Fig. 3).

\section{Research Hypothesis}

Figure 4 depicts a proposed research model comprising four concepts: social cues design, attitude toward the ad, self efficacy on recall, and design usage intention. The proposed four hypotheses $(\mathrm{H} 1, \mathrm{H} 2, \mathrm{H} 3$, and H4) in Figure 1 are introduced as follows.

Social cues design is defined as "a medium presents other persons' social interactions directly or indirectly in different levels". The social cues design in the check-in service has two purposes: self disclosure for personal promotion (Carpenter, 2012) and product and company promotion (Mangold and Faulds, 2009). Self promotion indicates that a person presents an inflated sense of self to as many people as possible (Carpenter, 2012). Product and company promotion in social media is an informal promotion channel that customers talk directly to one another about products and companies outside company managers' direct control.

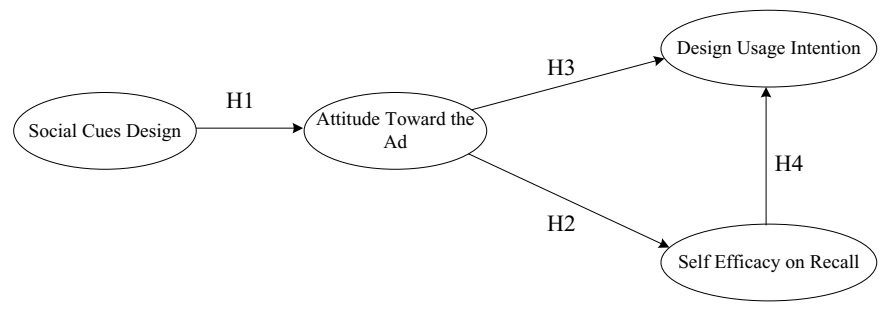

Fig. 4. Research Model

In the advertising domain, attitude toward the ad is the affective response of consumers to a particular stimulus (Wang et al., 2009; Yi, 1990). Attitude means users' feeling, such as good, interesting, like, and favorable. Social cues can evoke social presence (Horvath and Lombard, 2010). Social presence concerns with the human warmth and sociability on the Internet media (Hassanein and Head, 2006). Lombard and Ditton suggest that one of the most prominent psychological impact of social presence is positive attitude (Lombard and Ditton, 1997). Social presence causes enjoyable, interesting, and pleasant feelings in an apparel retailing website (Hassanein and Head, 2006). Therefore the hypothesis 1 is proposed as follows.

Hypothesis 1 (H1): The richness levels of social cues design positively influences attitude toward the ad in check-in based advertising. 
Self efficacy is the belief that a person is able to perform a particular task (Lorenzo et al., 2012; Compeau and Higgins, 1995). Recall means that a person remembers the received message after a period of time (Norris and Colman, 1992). Therefore Self efficacy on recall in this study is defined as "the belief that a person is able to remember the received message after a period of time". High pleasant feelings have a significant positive impact on advertising recall (Pieters and Klerk-Warmerdam, 1996). This study measures self efficacy on recall and does not measure actual recall accuracy because we would like to explore how users subjectively belief and confidence in recall the content can influence the intention to adopt a design in a check-in service. Furthermore, self-reported confidence in recall could be useful as a predictor of recall accuracy (Cust et al., 2009). Therefore self efficacy on recall can be a predictor of the actual recall accuracy. The hypothesis 2 is proposed as follows.

Hypothesis 2 (H2): Attitude toward the ad positively influences recall self efficacy in check-in based advertising.

The prior research shows that behavior intention to system use lead to actual system use (Moon and Kim, 2001). This study goes beyond the general check-in system usage intention and focus on the design preference in check-in system usage. Therefore design usage intention is defined as "behavior intention to post and share a particular richness level of social cues in check-in service usage".

People tend to share positive, good, and interesting content to others online (Tierney, 2013). People are most enthusiastic in spreading ideas that they themselves are excited and that appeals to others (Falk, et. al, 2013). Hence the hypothesis 3 and 4 are proposed as follows.

Hypothesis 3 (H3): Attitude toward the ad positively influences design usage intention in check-in based advertising.

Hypothesis 4 (H4): Self efficacy on recall positively influences design usage intention in check-in based advertising.

\section{Research Method}

This study manipulates social cue richness in the experiment setting. Table 1 summarizes three levels of social cues richness in check-in content. Subjects in experiments are randomly assigned in three groups to browse check-in content C-1, C-2, and C-3 on Facebook. The subjects were Taiwanese, and were university students.

After the subjects browse a particular check-in based advertisement, the subjects fill in the questionnaire to measure their attitude toward the ad, self efficacy on recall, and design usage intention. The items in the questionnaire for measuring attitude toward the ad is developed based on the advertisement effects study (Yi, 1990). The items in the questionnaire for measuring self efficacy on recall is based on the prior advertising recall studies (Norris and Colman, 1992; Bezjian-Avery et al., 1998). And the items of design usage intention are based on the concept of technology usage intention (Venkatesh et al., 2003). 
Table 1. Social Cues Richness in Check-in Design

\begin{tabular}{lll}
\hline $\begin{array}{l}\text { Social } \\
\text { Cues } \\
\text { Design }\end{array}$ & $\begin{array}{l}\text { Social } \\
\text { Cues } \\
\text { Richness }\end{array}$ & Features \\
\hline C-1 & Low & $\begin{array}{l}\text { Text: descriptions about the feeling of } \\
\text { the product in the location } \\
\text { Map: the geographic location in the map } \\
\text { is shown directly. } \\
\text { Text: as the same as C-1 } \\
\text { Picture: the product and scene in the } \\
\text { location } \\
\text { Map: the geographic location in the map } \\
\text { shows when a user clicks the location } \\
\text { name. } \\
\text { Text: as the same as C-1 } \\
\text { C-3 }\end{array}$ \\
& High & $\begin{array}{l}\text { Picture: the person, product, and scene in } \\
\text { the location } \\
\text { Map: the geographic location in the map } \\
\text { shows when a user clicks the location } \\
\text { name. }\end{array}$ \\
\hline
\end{tabular}

\section{$5 \quad$ Experimental Result}

The experimental result is twofold. The first part is descriptive statistic data for reporting user experiences. The second part is the hypotheses testing result conducted by partial least squares (PLS) regression technique. The two parts are introduced as follows.

\subsection{Descriptive Statistics}

The descriptive statistics reports the user experiences for three groups of social cues designs (C-1, C-2, and C-3) about attitude toward the ad, self efficacy on recall, and design usage intention. The sample size is 63 . The statistic data is shown and discussed as follows.

The subject demographics are shown in Table 2. In the experiment, male subjects are about 70 percent and female subjects are about 30 percent. Most of subjects are 18-28 years old. All subjects have usage experiences on Facebook. 82\% subjects have usage experiences on the Facebook check-in service. Most of subjects like to use the check-in service in sight-seeing spot $(63 \%)$, Leisure-oriented entertainment place $(66.2 \%)$, and restaurant $(69.2 \%)$.

Table 3 shows that higher social cues richness results in more subjects who have positive attitude toward the ad in average agreed percentage. It is interesting that the agreed percentage of irritating $(18.1 \%)$ and favorable $(45.4 \%)$ in high social cues richness (C-3) group is lower than the agreed percentage of irritating (26.0\%) and favorable $(56.5 \%)$ in medium social cues richness (C-2) group. In the follow-up 
study, a subject reports that the no-person photo (in C-2) keeps the sense of mystery to increase irritating feeling. Another subject does not favor product+person photo (in $\mathrm{C}-3$ ) because the person occupies most of the photo layout.

Table 2. Subject Demographics

\begin{tabular}{lc}
\hline Gender 7-2 & \\
\hline Male & $71.4 \%$ \\
\hline Female & $28.6 \%$ \\
\hline Dominant age group & $18-28$ \\
\hline Have Facebook usage experience & $100 \%$ \\
\hline Have check-in experience & $82.0 \%$ \\
\hline Preferred check-in locations & \\
\hline Public transportation & $29.2 \%$ \\
\hline Sight-seeing spot & $63.0 \%$ \\
\hline Government institution & $23.0 \%$ \\
\hline Leisure-oriented entertainment place & $66.2 \%$ \\
\hline Restaurant & $69.2 \%$ \\
\hline Activity and exhibition & $49.2 \%$ \\
\hline Others & $9.2 \%$ \\
\hline
\end{tabular}

Table 3. Agreed Percentage on Attitude Toward the Ad

\begin{tabular}{|llll|}
\hline Social Cues Richness & $\begin{array}{l}\text { Low } \\
\text { C-1 }\end{array}$ & $\begin{array}{l}\text { Medium } \\
\text { C-2 }\end{array}$ & $\begin{array}{l}\text { High } \\
\text { C-3 }\end{array}$ \\
\hline Good & $33.3 \%$ & $56.5 \%$ & $72.7 \%$ \\
\hline Interesting & $38.9 \%$ & $47.8 \%$ & $63.6 \%$ \\
\hline Like & $16.7 \%$ & $52.1 \%$ & $59.1 \%$ \\
\hline Irritating & $5.6 \%$ & $26.0 \%$ & $\mathbf{1 8 . 1 \%}$ \\
\hline Favorable & $22.2 \%$ & $56.5 \%$ & $\mathbf{4 5 . 4 \%}$ \\
\hline Average & $23.3 \%$ & $47.8 \%$ & $51.8 \%$ \\
\hline
\end{tabular}

Table 4 shows the average of agreed percentage on self efficacy on recall in both medium and high social cues richness are higher than 50\%. However, the average of agreed percentage on self efficacy on recall $(63.0 \%)$ in the medium social cues richness $(\mathrm{C}-2)$ group is higher than the average percentage $(53.6 \%)$ in the high social cues richness (C-3) group. And the average of agreed percentage on self efficacy on recall $(53.6 \%)$ in the high social cues richness group (C-3) is higher than the average percentage $(40.6 \%)$ in the low social cues richness (C-1) group. In more details, two items dramatically decrease the average of agreed percentage on self efficacy on recall in the high social cues richness (C-3) group: "The ad enhance my impression on the scene and product" and "I can describe the scene and product in the ad in few days". This result is reasonable because several subjects indicate that the product is too small in the photo layout and most of the photo layout is occupied by a person. 
Table 5 reveals that the subjects intend to use the higher social cues richness when they generating check-in based advertisement in general. It is interesting that only $36.4 \%$ subjects intend to use the high social cues richness design in the $\mathrm{C}-3$ group, which lower than $47.8 \%$ agreed percentage on design usage intention in the C-2 group. Subjects indicate that they sometimes take no-person photos for generating check-in based advertisement because of privacy concerns. For example, some persons secretly join the activities and are unsuitable for appearance in social media publicly. Many users often add unfamiliar "friends" in social media. Some users were afraid the person photos may be stolen by other unfamiliar persons for harmful purposes.

Table 4. Agreed Percentage on Self Efficacy on Recall

\begin{tabular}{|llll|}
\hline Social Cues Richness & $\begin{array}{l}\text { Low } \\
\text { C-1 }\end{array}$ & $\begin{array}{l}\text { Medium } \\
\mathbf{C - 2}\end{array}$ & $\begin{array}{l}\text { High } \\
\mathbf{C - 3}\end{array}$ \\
\hline $\begin{array}{l}\text { I can remember the } \\
\text { scene and product in } \\
\text { the ad in few days. }\end{array}$ & $38.9 \%$ & $69.5 \%$ & $68.2 \%$ \\
\hline $\begin{array}{l}\text { The ad enhance my } \\
\text { impression on the } \\
\text { scene and product. }\end{array}$ & $55.6 \%$ & $78.3 \%$ & $\mathbf{5 9 . 1 \%}$ \\
\hline $\begin{array}{l}\text { I can describe the sce- } \\
\text { ne and product in the } \\
\text { ad in few days. }\end{array}$ & $22.2 \%$ & $43.4 \%$ & $\mathbf{2 7 . 3 \%}$ \\
\hline $\begin{array}{l}\text { I will remember the ad } \\
\text { if similar scenes and } \\
\text { products appear. }\end{array}$ & $44.5 \%$ & $60.9 \%$ & $59.1 \%$ \\
\hline \multicolumn{1}{|c|}{ Average } & & \\
\hline
\end{tabular}

Table 5. Agreed Percentage on Design Usage Intention

\begin{tabular}{|llll|}
\hline Social Cues Richness & $\begin{array}{l}\text { Low } \\
\text { C-1 }\end{array}$ & $\begin{array}{l}\text { Medium } \\
\text { C-2 }\end{array}$ & $\begin{array}{l}\text { High } \\
\mathbf{C - 3}\end{array}$ \\
\hline $\begin{array}{l}\text { I would use this design } \\
\text { approach continuously. }\end{array}$ & $16.7 \%$ & 56.5 & $68.2 \%$ \\
\hline $\begin{array}{l}\text { I would choose this de- } \\
\text { sign approach. }\end{array}$ & $11.2 \%$ & 60.9 & $68.2 \%$ \\
\hline $\begin{array}{l}\text { I would use this design } \\
\text { approach to interact } \\
\text { with my friends. }\end{array}$ & $16.7 \%$ & 78.3 & $77.2 \%$ \\
\hline $\begin{array}{l}\text { I would not stop use this } \\
\text { design approach. }\end{array}$ & $22.3 \%$ & 47.8 & $\mathbf{3 6 . 4 \%}$ \\
\hline $\begin{array}{l}\text { I hope my check-in con- } \\
\text { tent would be made by } \\
\text { this design approach. }\end{array}$ & $11.2 \%$ & 60.9 & $81.8 \%$ \\
\hline \multicolumn{1}{|c|}{ Average } & 15.6 & 60.9 & 66.4 \\
\hline
\end{tabular}




\subsection{Hypotheses Testing Result}

In the data analysis phase for hypotheses testing, this study uses partial least squares (PLS), which is a structural equation modeling (SEM). PLS is useful when the sample size is not very large. Bootstrapping was performed to test the statistical significance of each path coefficient using t-tests. The result depicted in Figure 2 shows that increased social cues numbers in advertisement presentation design positively and significantly influences on attitude toward the ad. Attitude toward the ad has a positive and significant impact on self efficacy on recall and design usage intention. And self efficacy on recall has a positive and significant impact on design usage intention. Thus hypotheses H1, H2, $\mathrm{H} 3$, and $\mathrm{H} 4$ are supported. The $\mathrm{R}^{2}$ for the attitude construct in Figure 5 was rather low in 0.092. However, it is reasonable, because attitude for check-in content are affected by a large number of factors other than social cues design.

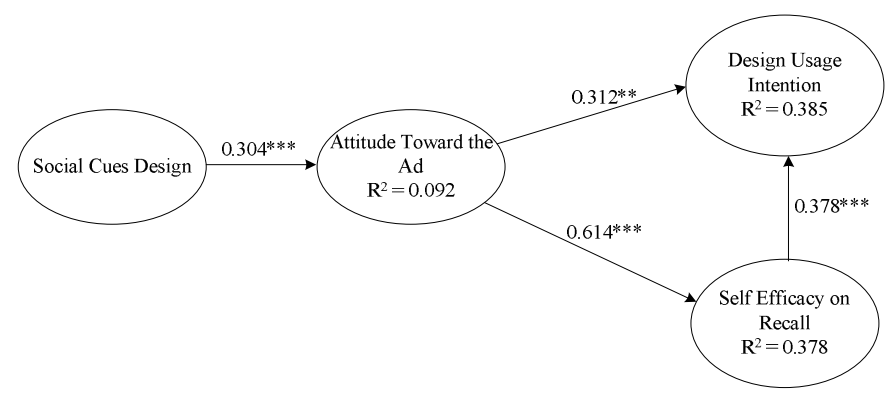

Fig. 5. PLS Structural Model

Notes: Values above the arrows refer to path coefficients; ${ }^{* *} \mathrm{p}<0.01,{ }^{* * *} \mathrm{p}<0.001$.

\section{Conclusion}

Check-in content can be considered as an informal advertising in users' self promotion and companies' promotion simultaneously in social media. This study proposes a research model involves social presence levels in check-in based advertisement, attitude toward the user-generated advertisement in a check-in service, self efficacy on recall, and design usage intention. The relationships among the above concepts are discussed based on the prior studies. The preliminary experiment for validating the proposed model is conducted.

In theoretical contribution, this study put the concept of attitude toward the ad into the social media's check-in service as an informal promotion channel in the proposed research model. The proposed model presents a virtuous circle for the promotion in social media. In this circle, users like receiving positive and interesting message. Others usually give positive feedbacks to admire these positive and interesting message in the expectation. And users would like to share a positive message about companies and products in check-in services. For managerial implications, companies should prepare attractive products and scenes to increase positive attitude toward the checkin message and users will more intend to share the message for promote companies and products informally in social media. 


\section{References}

1. Bezjian-Avery, A., Calder, B., Iacobucci, D.: New media interactive adverting vs. traditional advertising. Journal of Adverting Research 38(4), 23-32 (1998)

2. Cramer, H., Rost, M., Holmquist, L.E.: Performing a check-in: emerging practices, norms and 'conflicts' in location-sharing using Foursquare. In: Proc. 13th International Conference on Human Computer Interaction with Mobile Devices and Services (MobileHCI 2011), Stockholm, Sweden, pp. 57-66 (2011)

3. Carpenter, C.J.: Narcissism on Facebook, self-promotional and anti-social behavior. Personality and Individual Differences 52(4), 482-486 (2012)

4. Compeau, D.R., Higgins, C.A.: Computer self-efficacy: development of a measure and initial test. MIS Quarterly 19(2), 189-211 (1995)

5. Cust, A.E., Armstrong, B.K., Smith, B.J., Chau, J., van der Ploeg, H.P., Bauman, A.: Selfreported confidence in recall as a predictor of validity and repeatability of physical activity questionnaire data. Epidemiology 20(3), 433-441 (2009)

6. Falk, E.B., Morelli, S.A., Welborn, B.L., Dambacher, K., Lieberman, M.D.: Creating buzz: the neural correlates of effective message propagation. Psychological Science 24(7), 1234$1242(2013)$

7. Hassanein, K., Head, M.: The impact of infusing social presence in the web interface: an investigation across product types. International Journal of Electronic Commerce 10(2), 31-55 (2006)

8. Horvath, K., Lombard, M.: Social and spatial presence: an application to optimize humancomputer interaction. PsychNology Journal 8(1), 85-114 (2010)

9. $\mathrm{Hu}, \mathrm{H}$. , Jasper, C.R.: Social cues in the store environment and their impact on store image. International Journal of Retail \& Distribution Management 34(1), 25-48 (2006)

10. Kamins, M.A., Noy, A., Steinhart, Y., Mazursky, D.: The effect of social cues on sniping behavior in Internet auctions: field evidence and a lab experiment. Journal of Interactive Marketing 25(4), 241-250 (2011)

11. Lombard, M., Ditton, T.: At the heart of it all: the concept of presence. Journal of Computer Mediated Communication 3(2), 1-18 (1997)

12. Lorenzo, O., Kawalek, P., Ramdani, B.: Enterprise applications diffusion within organizations: a social learning perspective. Information \& Management 49(1), 47-57 (2012)

13. Mangold, W.G., Faulds, D.J.: Social media: The new hybrid element of the promotion mix. Business Horizons 52(4), 357-365 (2009)

14. Moon, J.W., Kim, Y.G.: Extending the TAM for a World-Wide-Web context. Information \& Management 38(4), 217-230 (2001)

15. Norris, C.E., Colman, A.M.: Context effects on recall and recognition of magazine advertisements. The Journal of Advertising 21(3), 37-46 (1992)

16. Pieters, R.G.M., Klerk-Warmerdam, M.D.: Ad-evoked feeling: structure and impact on Aad and recall. Journal of Business Research 37(2), 105-144 (1996)

17. Venkatesh, V., Morris, M.G., Davis, G.B., Davis, F.D.: 'User acceptance of information technology: toward a unified view'. MIS Quarterly 27(3), 425-478 (2003)

18. Wang, L.C., Baker, J., Wagner, J.A., Wakefield, K.: Can a retail web site be social? Journal of Marketing 71, 143-157 (2007)

19. Wang, K., Wang, E.T.G., Farn, C.K.: Influence of web advertising strategies, consumer goal-directedness, and consumer involvement on web advertising effectiveness. International Journal of Electronic Commerce 13(4), 67-95 (2009)

20. Yi, Y.: Cognitive and Affective Priming Effects of the Context for Print Advertisement. Journal of Advertising 19(2), 40-48 (1990) 